\title{
A Coupled Sea Ice-Mixed Layer-Pycnocline Model for the Weddell Sea
}

\author{
P. LEMKE' \\ Max-Planck-Institut für Meteorologie, Hamburg, Federal Republic of Germany \\ W. B. OWENS
}

Woods Hole Oceanographic Institution, Woods Hole, Massachusetts

W. D. HibLer III

Dartmouth College, Hanover, New Hampshire

\begin{abstract}
A dynamic-thermodynamic sea ice model is coupled to a one-dimensional model of the oceanic mixed layer and pycnocline and is applied to the Weddell Sea. This model prognostically determines the vertical oceanic heat flux from the mixed layer dynamics in contrast to earlier sea ice modeling where the oceanic heat flux was prescribed. In addition to the standard simulation, polynya and paleoclimate experiments were performed to investigate the effects of sea ice dynamics. Furthermore, the mixed layer-pycnocline model is compared to the original Kraus-Turner approach.
\end{abstract}

\section{INTRODUCTION}

The seasonal variation of Antarctic sea ice is one of the strongest climate signals on the Earth's surface. Before undertaking a simulation of the entire Antarctic region, it is appropriate to first model the Weddell Sea ice pack. Weddell Sea ice makes up a major portion of the Antarctic ice cover and can be considered typical of the Antarctic region. It is also somewhat better sampled than the remainder of the Southern Ocean. The formation of sea ice near the continental margin and melting at the ice edge are also important processes in the production of surface and bottom water masses [Toole, 1981; Foster and Carmack, 1976; Ackley, 1979]. As a result, long-term variations in both the annual average and seasonal cycle of the Weddell Sea ice pack can have a strong influence on climatic conditions both through changes in the surface albedo and temperature and by changes in the production of ocean water masses which would indirectly alter the deep circulation in the world's oceans.

Using the microwave radiometer on the Nimbus 5 satellite, an extensive data set on sea ice extent and distribution around the Antarctic continent has been collected since the early 1970s [Zwally et al., 1983]. In situ measurements have also provided ground truth in the Weddell Sea for the atmospheric data collected as part of the First GARP Global Experiment (FGGE) [Ackley, 1981]. Thus, using appropriate analyses of this wind field data and standard empirical formulae for solar radiation, the requisite forcing fields for a sea ice model can be obtained [Hibler and Ackley, 1983]. Limited observations [Ackley, 1979; Wadhams et al., 1987] also provide typical ice thickness values, so that estimates of the total ice volume can be made.

\footnotetext{
${ }^{1}$ Now at Alfred Wegener Institute for Polar and Marine Research, Bremerhaven, Federal Republic of Germany.

Copyright 1990 by the American Geophysical Union.

Paper number 89JC03747.

0148-0227/90/89JC-03747\$05.00
}

The ocean currents in the region form the well-known Weddell Sea gyre [Deacon, 1979; Gordon et al., 1981]. Although there are sufficient temperature and salinity observations to determine the baroclinic part of the velocity field, only the drift of a few satellite-tracked buoys and ships' drift are available to estimate the barotropic flow [Gordon et al., 1981]. Nevertheless, these measurements allow us both to prescribe the oceanic geostrophic currents if one neglects oceanic advective effects in the coupled sea ice-mixed layer model and to compare (in gross aspects) our predicted ice motions. The relatively large, $O(10-30 \mathrm{~cm} / \mathrm{s})$ ice motions in the western Weddell Sea also suggest that advective effects must be considered in any description of the ice dynamics.

Estimates of the oceanic heat flux into the base of the mixed layer, which must then enter the ice cover, range from 4 to $20 \mathrm{~W} / \mathrm{m}^{2}$ [Gordon, 1981]. It is believed that this has large spatial gradients, with large values near the continental margin where ice is formed and relatively small values under the central part of the ice pack. These values will be compared with those prognostically determined from our coupled sea ice-mixed layer model.

The first simulations of the seasonal cycle of ice extent in the Weddell Sea considered only the local, thermodynamic response of sea ice to atmospheric forcing with a prescribed oceanic heat flux [Washington et al., 1976]. Parkinson and Washington [1979] improved the sea ice model by adding a simplified advective scheme. Using a more sophisticated dynamic model developed earlier for Arctic simulations [Hibler, 1979] which included momentum conservation, advection, and thermodynamic growth and decay, Hibler and Ackley [1983] and Hibler [1984] demonstrated that dynamic effects must be included to give a realistic simulation of the seasonal cycle of ice extent in the Weddell Sea. In the above studies the interaction with the ocean, expressed as a heat flux from the ocean into the base of the sea ice, was either prescribed or treated, in an ad hoc manner, as a fraction of the atmospheric cooling rate. In a recent paper [Lemke, 1987] a prognostic, one-dimensional mixed layer model with a well mixed layer overlying an exponentially varying pyc- 
nocline, was coupled to a one-dimensional, thermodynamic ice model, similar to the thermodynamic code used by Parkinson and Washington [1979]. Presented in this paper are the results from a model which couples a dynamic sea ice model [Hibler and Ackley, 1983] to one-dimensional mixed layer models, both that used by Lemke [1987] and one based on the two-slab layer formulation of Kraus and Turner [Niiler and Kraus, 1977]. Effects of horizontal advection in the mixed layer model are crudely parameterized here, but will be investigated in more detail in a subsequent publication.

In the next section, a short description of the model dynamics as well as the model domain and integration procedure are given. In the following section, it is shown that the coupled model successfully simulates both the seasonal extent of sea ice and the average and spatial distributions of heat and salt fluxes into the ocean. A series of model simulations demonstrates the sensitivity of the results to the dynamics of the ocean mixed layer. A set of experiments investigating the collapse of polynyas after they are formed by anomalous oceanic heating suggests that advective effects coupled with the thermodynamics and mixed layer dynamics create a strong negative feedback system, damping the response to these short-time perturbations and restoring the model back toward the original seasonal cycle. This system eliminates a polynya much faster than a thermodynamics-only model. Finally, a set of experiments with atmospheric and oceanic conditions similar to those of earlier paleoclimatic periods also show this strong, negative feedback.

In this paper we will mainly focus on effects associated with the ocean part of the model. The problems concerning the sea ice dynamics and snow cover are addressed by Owens and Lemke [this issue], and the extension of the model domain to the entire Southern Ocean is presented by Stössel et al. [this issue].

\section{Description OF THE MOdeL}

The approach used in this study couples a two-layer dynamic-thermodynamic sea ice model [Hibler, 1979] with a one-dimensional, prognostic mixed layer [Lemke, 1987]. Basically, the sea ice model consists of a momentum balance coupled to ice thickness and compactness (fraction of area covered by sea ice) equations. In the latter equations the oceanic heat flux is determined by the mixed layer dynamics which also prescribes the depth, temperature, and salinity of the mixed layer and the underlying layer. We will give a brief description of the model here to show how we have coupled the two models.

\subsection{Ice Momentum Equation}

The momentum equation, written in cartesian coordinates is

$$
m D \mathbf{u} / D t=-m f \mathbf{k} \times \mathbf{u}+\tau_{a}+\tau_{w}-m g \nabla H+\mathbf{F}
$$

where $u$ is the sea ice velocity, $m$ is the sea ice mass per unit area, $f$ is the Coriolis parameter and $g$ is the gravitational acceleration. Equation (1) includes inertial terms, Coriolis force, wind $\left(\tau_{a}\right)$ and water $\left(\tau_{w}\right)$ stresses, surface tilt $H$, and internal ice interactions $\mathbf{F}$. The wind and water stresses are determined by integral boundary layers assuming constant turning angles [e.g., McPhee, 1979]. The surface tilt is related to the prescribed ocean currents using geostrophy.

The internal ice forces can be written in terms of the divergence of the two-dimensional stress tensor, $\mathbf{F}=\boldsymbol{\nabla} \cdot \boldsymbol{\sigma}$. Following Hibler [1979], the ice is considered to have a nonlinear viscous-plastic constitutive law

$$
\sigma_{i j}=2 \eta\left(\dot{\varepsilon}_{i j}, P\right) \dot{\varepsilon}_{i j}+\left[\left(\zeta\left(\dot{\varepsilon}_{i j}, P\right)-\eta\left(\dot{\varepsilon}_{i j}, P\right)\right) \dot{\varepsilon}_{k k}-P / 2\right] \delta_{i j}
$$

where $\dot{\varepsilon}_{i j}$ is the strain rate tensor, $P / 2$ is a pressure term related to the ice thickness, $\dot{\varepsilon}_{k k}=\dot{\varepsilon}_{11}+\dot{\varepsilon}_{22}$ is the ice divergence, and $\zeta$ and $\eta$ are the nonlinear bulk and shear viscosities, respectively. The viscous-plastic constitutive law [Hibler, 1979] prescribes

$$
\zeta=P / 2 \Delta \quad \eta=\zeta / e^{2}
$$

where

$$
\Delta=\left[\left(\dot{\varepsilon}_{11}^{2}+\dot{\varepsilon}_{22}^{2}\right)\left(1+1 / e^{2}\right)+4 \dot{\varepsilon}_{12}^{2} / e^{2}+2 \dot{\varepsilon}_{11} \dot{\varepsilon}_{22}\left(1-1 / e^{2}\right)\right]^{1 / 2}
$$

and $e$ is the ratio of the principal axes of the elliptical yield curve. The viscosities are confined to finite values as the strain rates become small by limiting their values to be less than

$$
\zeta_{\max }=\left(2.5 \times 10^{8} \mathrm{~s}\right) P \quad \eta_{\max }=\zeta_{\max } / e^{2}
$$

The ice strength is coupled to ice thickness characteristics according to

$$
P=P^{*} h_{i} \exp (-C(1-A))
$$

where $h_{i}$ is the average ice thickness in a grid cell and $A$ is the ice compactness or fraction of the area covered by ice. The actual ice thickness of the ice-covered part of a grid cell is therefore given by $h_{i} / A$.

In this formulation there are three model parameters that must be specified a priori, the ratio of principal axes, $e$, and the yield strength parameters $P^{*}$ and $C$. For this study we have used the same values as Hibler and Ackley [1983], $e=$ $2, P^{*}=2.75 \times 10^{4} \mathrm{~N} / \mathrm{m}^{2}$, and $C=20$.

\subsection{Ice Thickness Conservation Equations}

Local changes in ice thickness and compactness are computed from continuity equations for these variables,

$$
\begin{gathered}
\dot{h}_{i}=-\nabla \cdot\left(\mathbf{u} h_{i}\right)+S_{h}+\text { diffusion } \\
\dot{A}=-\nabla \cdot(\mathbf{u} A)+S_{A}+\text { diffusion }+S_{o p}
\end{gathered}
$$

where $A \leq 1$. The diffusion terms are small and introduced solely for numerical purposes. $S_{h}$ and $S_{A}$ are thermodynamic growth terms given by

$$
\begin{array}{rrr}
S_{h}=A f\left(h_{i} / A\right)+(1-A) f(0)- & Q_{o} /\left(\rho_{i} L\right) \\
S_{A}=(1-A) f(0) / h_{0}+x & f(0) & >0 \\
S_{A}=0+x & f(0) & <0
\end{array}
$$

where

$$
\begin{array}{ll}
x=0 & S_{h}>0 \\
x=\left(A / 2 h_{i}\right) S_{h} & S_{h}<0
\end{array}
$$


where $f(h)$ is the growth rate for ice thickness $h . S_{o p}$ is a term representing the creation of open water by shear deformation [Hibler, 1984]. The growth rates are determined from conductive heat fluxes through the ice which arise from conservation of energy at the upper ice surface [Semtner, 1976; Parkinson and Washington, 1979]. The $S_{h}$ term is the sum of the ice growth over both open water and that part of the grid cell covered by ice. Since the growth rate, $f(h)$, is a highly nonlinear function of ice thickness and, in reality, each cell is covered by a distribution of ice thicknesses which give the average thickness, $h_{i}$, we have followed the procedure of Hibler [1984] and estimated the growth rates $f(h)$ from an equal, seven-level distribution between zero and twice the average thickness. $Q_{o}$ in (8) denotes the vertical oceanic (entrainment) heat flux which is determined from the mixed layer model; $\rho_{i}$ and $L$ are the density of sea ice and the latent heat of fusion, respectively.

The $S_{A}$ term characterizes how the growth rates of thick and thin ice affect the areal fraction of ice coverage. The first term in (9) parameterizes the closing of leads and open water under freezing conditions. It is assumed that the open water is not instantly covered by ice, but rather that the fraction of open water decays exponentially at a rate of $h_{0} / f(0)$. For example, in the Antarctic frazil ice formation, followed by strong wind events redeposits thin ice under the ice floes [Ackley et al., 1980; L. Lewis, personal communication, 1988] which tends to slow the closing of open water. Nevertheless, although $h_{0}$ has a physical basis, and we estimate that this decay rate is of the order of 5 days, the exact value of $h_{0}$ is not known and is an important model parameter. For this study a value of $0.5 \mathrm{~m}$ has been used.

The second term $(x)$ in (9) accounts for the decrease in the fraction of the area covered by ice due to the melting of thick ice, assuming its thickness is distributed between 0 and twice $h_{i} / A$ and all the ice melts at the same rate.

\subsection{Oceanic Mixed Layer-Pycnocline Model}

The vertical structure of the one-dimensional mixed layerpycnocline model used here to represent the upper ocean is shown in Figure 1. Temperature and salinity are constant within the mixed layer and have an exponential profile within the pycnocline.

$$
\begin{array}{ll}
T(z)=T \quad S(z)=S \quad 0>z>-h \\
T(z)=T_{\infty}+\left(T-T_{\infty}\right) \exp \left[(z+h) / d_{T}\right] \\
S(z)=S_{\infty}+\left(S-S_{\infty}\right) \exp \left[(z+h) / d_{S}\right] \quad-h>z>-h_{b}
\end{array}
$$

The prognostic variables are the mixed layer temperature $T$ and salinity $S$, the mixed layer depth $h$, and the $e$-folding depths of the thermocline $d_{T}$ and halocline $d_{S}$. The prognostic equations of the mixed layer-pycnocline model are derived from the conservation of heat and salt, potential energy considerations, and a parameterization for the entrainment heat and salt fluxes. Details are given by Lemke [1987]. The lower level of the model, $h_{b}$, is set at $3000 \mathrm{~m}$. Generally, the scale depths of the thermocline and halocline, $d_{S}, d_{T}$ are much less than $h_{b}-h$, so that $T_{b}=T\left(-h_{b}\right) \approx T_{\infty}$ and $S_{b}=S\left(-h_{b}\right) \approx S_{\infty} . T_{b}$ and $S_{b}$ are considered as given boundary conditions and taken to be constant in space and time with typical values for the Weddell Sea, $0.6^{\circ} \mathrm{C}$ and $34.8 \%$, respectively.

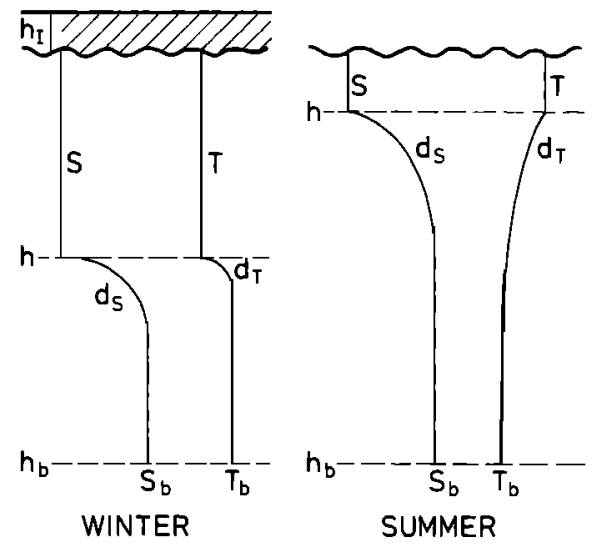

Fig. 1. Vertical structure of the mixed layer-pycnocline model.

The model equations are

$$
\begin{gathered}
\dot{S}=\left(Q_{S}+\left(S^{*}-S\right) W_{e}\right) / h \\
\dot{T}=\left(Q_{T}+\left(T^{*}-T\right) W_{e}\right) / h \\
\dot{d}_{S}=d_{S} /\left(S_{b}-S\right) \dot{S}+\left(\left(S^{*}-S\right) /\left(S_{b}-S\right)-1\right) W_{e} \\
\dot{d}_{T}=d_{T} /\left(T_{b}-T\right) \dot{T}+\left(\left(T^{*}-T\right) /\left(T_{b}-T\right)-1\right) W_{e} \\
\dot{h}=W_{e}-W
\end{gathered}
$$

where $Q_{S}$ and $Q_{T}$ are the surface fluxes of salt and heat, respectively, which are determined from the sea ice model. $S^{*}$ and $T^{*}$ denote the mean salinity and temperature in the entrainment zone of thickness $\delta(=8 \mathrm{~m})$, which is not resolved by the model,

$T^{*}=\frac{1}{\delta} \int_{-h-\delta}^{-h} T(z) d z=T_{b}$

$$
+\left(T_{b}-T\right) d_{T}\left(\exp \left(-\delta / d_{T}\right)-1\right) / \delta
$$

$S^{*}=\frac{1}{\delta} \int_{-h-\delta}^{-h} S(z) d z=S_{b}$

$$
+\left(S_{b}-S\right) d_{s}\left(\exp \left(-\delta / d_{S}\right)-1\right) / \delta
$$

such that

$$
\begin{aligned}
& T^{*}-T=a_{T}\left(T_{b}-T\right) \\
& S^{*}-S=a_{S}\left(S_{b}-S\right)
\end{aligned}
$$

where

$$
a_{S, T}=1+d_{S, T}\left(\exp \left(-\delta / d_{S, T}\right)-1\right) / \delta
$$

Here, $a_{S, T}$ are the fractions of the salt or temperature difference between the mixed layer and the base of the second layer used in the calculation of the entrainment fluxes. Note that for this mixed layer model these are prognostic variables while they are fixed values $(=1.0)$ for the original Kraus-Turner model [Niiler and Kraus, 1977].

The entrainment velocity $W_{e}$ is given by

$$
W_{e}=\left(2 K D_{1}+h Q^{*} D_{2}\right) /\left(h\left(E+E^{*}\right)\right)
$$

with 


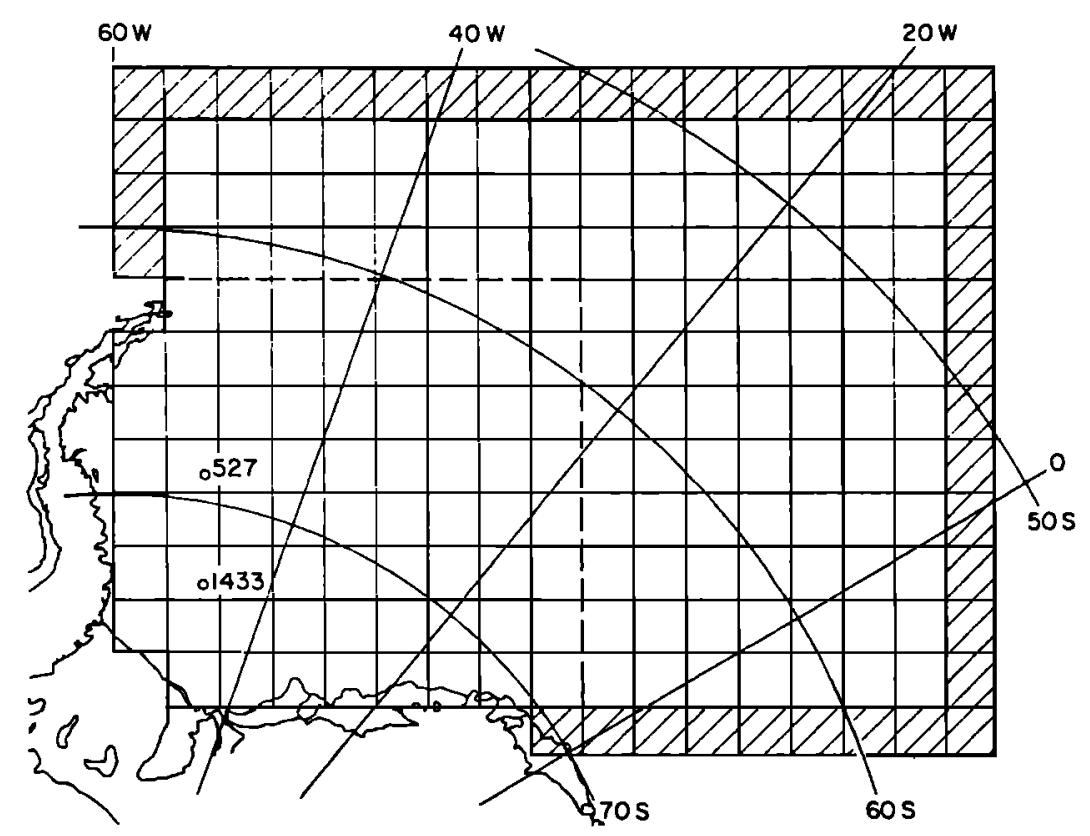

Fig. 2. Grid used for numerical simulations [from Hibler and Ackley, 1983].

$$
\begin{gathered}
K=\tilde{K} / g \\
E=\beta\left(S^{*}-S\right)-\alpha\left(T^{*}-T\right) \\
E^{*}=\left(\beta c\left(S-S_{I}\right) /\left(\rho_{w} L\right)-\alpha\right)\left(T^{*}-T\right) \\
Q^{*}=\beta\left(S-S_{I}\right) Q_{A} /\left(\rho_{w} L\right)-\beta F S
\end{gathered}
$$

where $\tilde{K}$ denotes the kinetic energy input due to wind and ice keel stirring, $\left(1-D_{1}\right)$ and $\left(1-D_{2}\right)$ represent the (depth dependent) dissipation of mechanical and convective energy input at the sea surface, $g$ is the gravitational acceleration, $\alpha$ and $\beta$ represent the expansion coefficients of the density with respect to temperature and salinity, $c=4.26 \times 10^{6}$ $\mathrm{J} / \mathrm{m}^{3} \mathrm{~K}$, and $S_{I}$ is the salinity of sea ice taken to be $5 \% . Q_{A}$ is the atmospheric freezing rate determined from the ice model

$$
Q_{A}=S_{h}+Q_{o} /\left(\rho_{i} L\right)
$$

where the oceanic heat flux is given by

$$
Q_{o}=\left(T^{*}-T\right) W_{e}
$$

$F$ is the net surface freshwater flux determined by the excess of precipitation over evaporation, and $\rho_{w}$ is the density of seawater.

The above equations apply only for the deepening of the mixed layer (entrainment phase, $W_{e}>0$ ). During the period of increased heating (melting) the stress-induced energy at the surface is generally insufficient to overcome the stabilizing effect of the surface buoyancy flux $\left(W_{e}<0\right)$. In this case the mixed layer retreats to an equilibrium depth, $\hat{h}$, given diagnostically by the Monin-Obukhov length which is determined by (21) with $W_{e}=0$ or

$$
2 K D_{1}+\hat{h} Q=0
$$

Changes of the surface salinity and temperature during the retreat phase are determined from (11) and (12), respectively, with $W_{e}=0$. The thermocline and halocline varia- bles, $d_{T}$ and $d_{S}$, finally are determined from the conservation of heat and salt, respectively.

According to the Arctic Ice Dynamics Joint Experiment (AIDJEX) analysis [McPhee and Smith, 1976] the kinetic energy input, $\bar{K}$, is computed from the simulated sea ice velocity $u$ relative to the prescribed ocean currents

$$
\tilde{K}=C_{w}|u|^{3} \cos \gamma
$$

where $\gamma$ is the frictional turning angle, found to be $24^{\circ}$, and the drag coefficient $C_{w}$ was estimated to be 0.005 .

In addition to the standard mixed layer model described above, the original Kraus-Turner two-layer model was applied. This model can be obtained from the equations above by setting $d_{S}=d_{T}=\dot{d}_{S}=\dot{d}_{T}=0$. Then (20) is replaced by $a_{S, T}=1$, and $T^{*}=T_{b}, S^{*}=S_{b}$, where $T_{b}$ and $S_{b}$ now denote the temperature and salinity, respectively, of the second layer.

The sea ice motion in the Weddell Sea creates regions with annual net melting and freezing. In order to keep the salinities in those areas from decreasing or increasing indefinitely we have applied a Newtonian damping which couples the mixed layer salinities to observation with a time constant of one year. This is a crude attempt to include advective effects in our one-dimensional model. A more sophisticated three-dimensional model with realistic advection is in preparation.

\subsection{Model Domain}

The model equations described above were solved on a nominal $2^{\circ}$ grid (Figure 2), which is the same as that used by Hibler and Ackley [1983]. The continental boundaries are closed while the hatched grid cells are considered to be open boundaries treated in the same manner as Hibler [1979]. The atmospheric forcing fields were also those used by Hibler and Ackley [1983], and consisted of a yearlong series of daily atmospheric data derived from the Australian analysis of the 1979 FGGE winds and solar radiation estimated from empir- 
ical parameterizations similar to those used by Parkinson and Washington [1979]. Prescribed geostrophic ocean currents were those calculated from historical hydrographic data given by Gordon et al. [1978]. It should be noted that the use of this set of forcing fields, some from real data and some from climatic conditions, which do not coincide with the satellite observations of the seasonal cycle of ice extent, precludes any detailed comparisons between model predictions and observations. Thus any fine tuning of the model parameters for optimal, minimal errors between the predicted fields and observations is not appropriate.

Initially the model was integrated with a fixed mixed layer depth for four years, starting with $2 \mathrm{~m}$ of ice everywhere, $100 \%$ compactness, and a fixed oceanic heat flux of $2 \mathrm{~W} / \mathrm{m}^{2}$. This produced an ice field for January 1 similar to that described by Hibler and Ackley [1983]. These distributions of ice thickness, compactness, and mixed layer temperatures were then used as initial conditions for our model studies. This procedure avoided the very long time that would have been required for the mixed layer dynamics to remove the artificially large freshwater flux due to the initial conditions used in previous studies. The coupled sea ice-mixed layer model was then integrated for a further four years to allow it to reach a cyclostationary state. Analysis of an integration for a final fifth year was used to describe the results.

\section{Results}

\subsection{Standard Experiment}

The seasonal cycle of the integrated ice covered area (Figure 3, upper panel, solid line) compares sufficiently well with observations (dotted line). The model could be tuned to fit better, but without a complete ocean circulation model this tuning does not seem to be reasonable. The seasonal cycle of the integrated sea ice mass (Figure 3, lower panel, solid line) shows an ice mass which is $\mathbf{4}$ times larger in winter than in summer.

The most important quantity describing the sea ice-ocean interaction is the entrainment heat flux $\left(Q_{o}\right)$. This vertical oceanic heat flux is presented in Figure 4 (lower panel, solid line) together with the average atmospheric freezing rate, $Q_{A}$, (upper panel, solid line) for the ice-covered part of the model grid. The oceanic heat flux does not show as pronounced a seasonal cycle as the atmospheric freezing rate does. To test the mechanism that creates significant vertical heat fluxes even in summer, in one experiment the kinetic energy input at the ocean surface was held constant in space and time representing an ice velocity of $0.1 \mathrm{~m} / \mathrm{s}$. The vertical oceanic heat flux for this run shows a distinct seasonal cycle (Figure 4, lower panel, dashed line) with the largest values in midwinter around day 240 , but the phase is different from that of the atmospheric freezing rate. Comparing the dashed and solid lines in the lower panel of Figure 4, it is apparent that the variations of the sea ice velocity (i.e., the surface kinetic energy input) provide most of the large entrainment heat fluxes in summer.

The September mean ice velocity (Figure 5) shows the well known gyre circulation with sea ice being formed in the southern part of the Weddell Sea, transported northward and then eastward and melted at the ice edge in the northeastern Weddell Sea. As a result of this flow field the sea ice is thinner (Figure 6) in the southern part of the grid (divergent

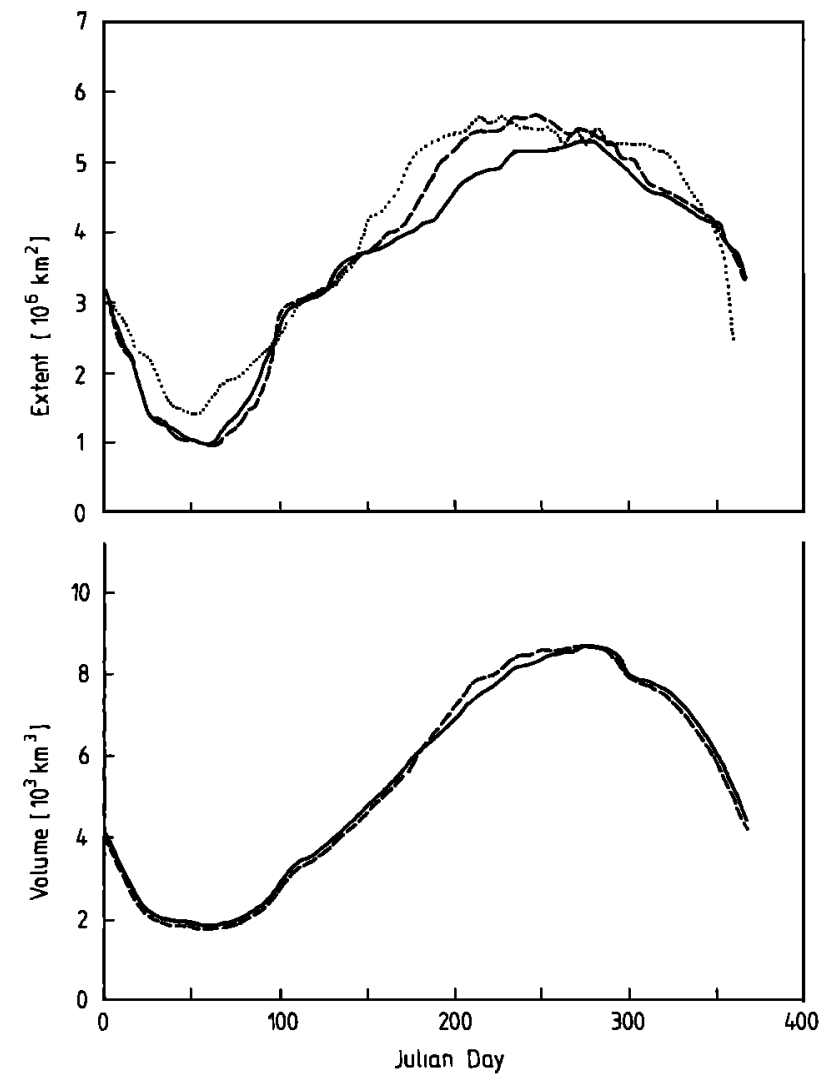

Fig. 3. Seasonal cycle of the integrated ice-covered area (upper panel) and ice volume (lower panel) in the Weddell Sea for the standard experiment (solid lines) and the experiment with the fixed mixed layer depth (dashed lines). Shown also is the observed integrated ice area (dotted line).

drift) and thicker at the western wall, the Antarctic Peninsula. The ice thickness in the eastern part of the grid is in agreement with observations [Wadhams et al., 1987].

In the divergent drift zone strong freezing rates and subsequent brine convection give the deepest (up to $270 \mathrm{~m}$ ) winter mixed layer (Figure 7). The geographical distribution of the mean oceanic heat flux in September is shown in Figure 8. Over most of the model domain it is about $2 \mathrm{~W} / \mathrm{m}^{2}$, but at the ice edge and in the divergent drift region in the southern Weddell Sea, where the freezing rates are largest, it increases up to $14 \mathrm{~W} / \mathrm{m}^{2}$. This increase is the result of entrainment of warmer water into the mixed layer which is mainly due to convective overturning caused by brine rejection during freezing. The simulated heat fluxes at the ice edge are close to observations by Gordon et al. [1984] which were taken up to $400 \mathrm{~km}$ inside the ice pack. The pronounced spatial variation of the simulated heat flux suggests that the extrapolation by Gordon et al. [1984] to estimate the total heat flux in the Weddell Sea may give too large a value.

In addition to the entrainment velocity and the temperature profile shape $\left(d_{T}\right)$ the modeled entrainment heat flux depends on the parameter $\delta$ which determines the thickness of the entrainment zone and therefore the effective temperature difference at the base of the mixed layer (equation (20)). From Arctic data [Lemke, 1987] $\delta$ was determined to be $8 \mathrm{~m}$. Experiments with larger values for $\delta$ yielded larger oceanic heat fluxes which were in better agreement with estimates from Gordon et al. [1984] for the total heat flux, 


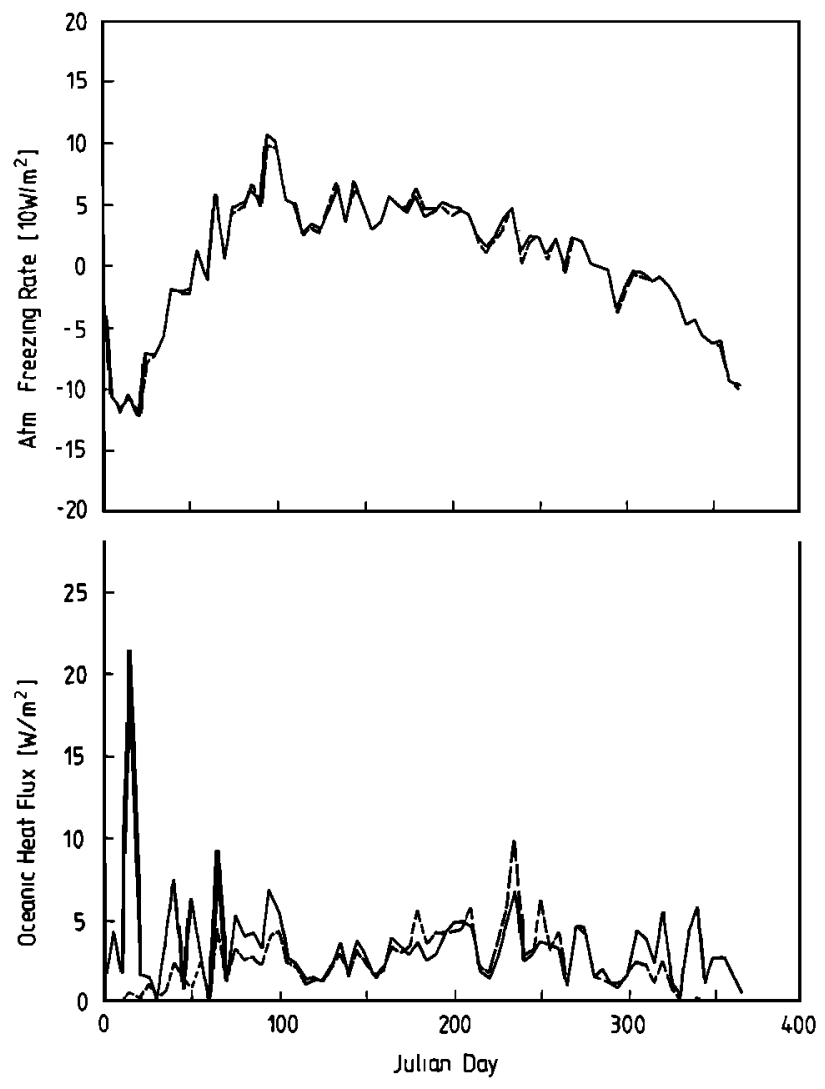

Fig. 4. Seasonal cycle of the atmospheric freezing rate (upper panel) and the entrainment heat flux into the mixed layer (lower panel) for the standard experiment (solid lines) and the experiment with the constant kinetic energy input (dashed lines).

but the seasonal cycle of sea ice extent in these experiments was poorer compared to observations than the standard run.

The effects of the velocity field are also apparent in the pattern of the annual net freezing rate (Figure 9). In the southern part of the grid up to $3 \mathrm{~m}$ of ice is frozen per year, is transported through the Weddell gyre, and is finally melted at the ice edge. This ice transport and net freezing rate is also

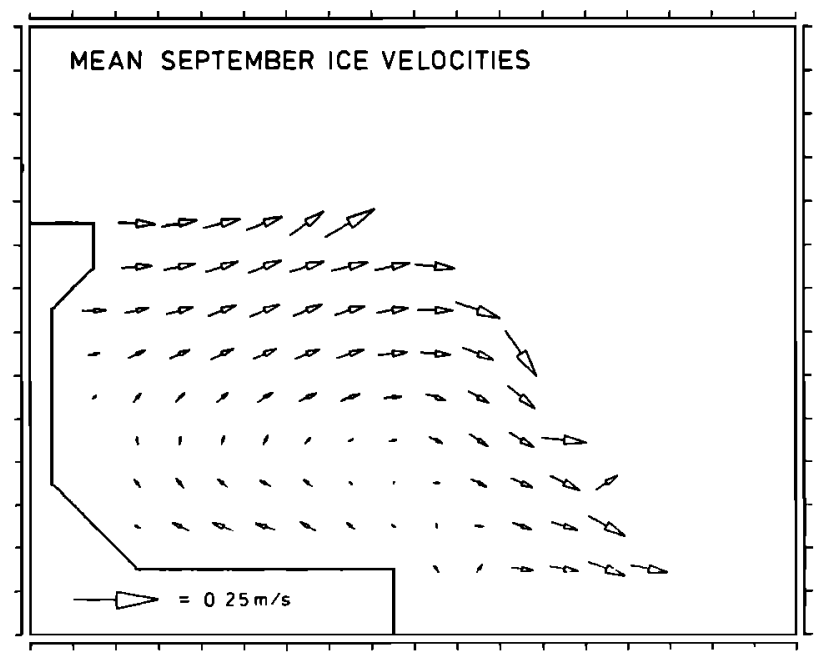

Fig. 5. Simulated mean September sea ice velocities in the Weddell Sea for the standard experiment.

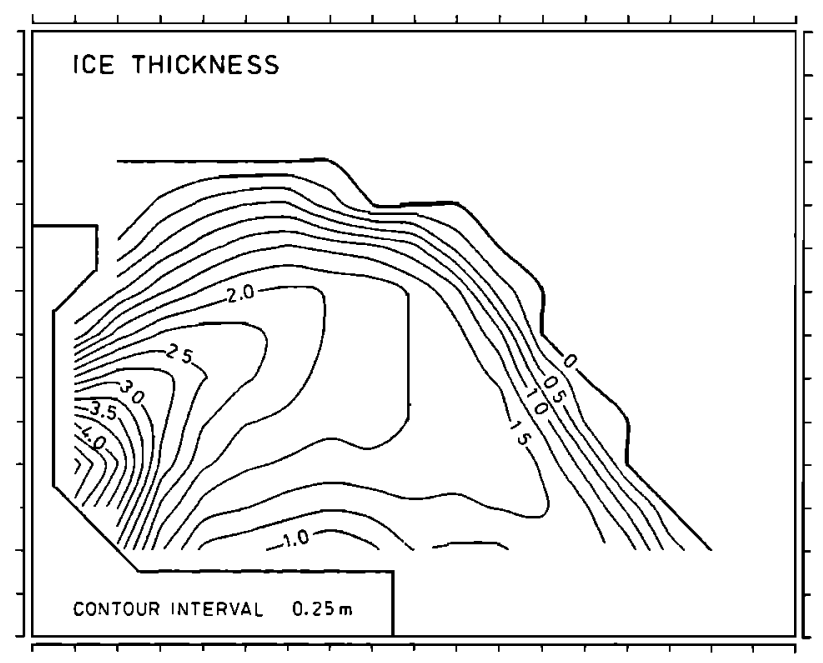

Fig. 6. Simulated standard sea ice thickness in the Weddell Sea on October 6.

reflected in the geographical distribution of the surface salinity (Figure 10). The salinity is largest in the southern part of the grid, and there is a pronounced salinity minimum at the ice edge. If advection in the mixed layer model were included, these large horizontal gradients would be reduced by transport of salty water northward and fresher water southward by the Weddell gyre circulation.

\subsection{Comparison to Fixed Mixed Layer}

The "fixed mixed layer" case uses a slab model with a prognostic temperature and salinity, but with a fixed mixed layer depth. A constant heat flux equal to the mean of the standard experiment $\left(3.26 \mathrm{~W} / \mathrm{m}^{2}\right)$ is supplied from the deep ocean. The resulting spatial patterns of the sea ice and mixed layer variables are similar to those for the prognostic mixed layer model. However, the seasonal cycles of the total volume and the extent are different (Figure 3). The mean and the seasonal amplitudes of the volume are similar, but the winter maximum occurs slightly earlier in the fixed mixed layer case. The extent shows a similar minimum in summer,

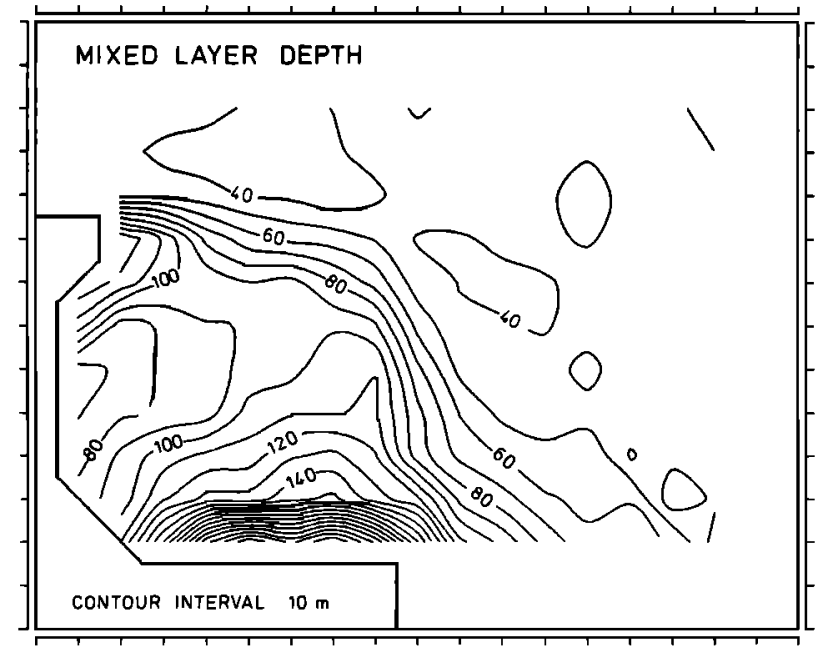

Fig. 7. Simulated standard mixed layer depth in the Weddell Sea on October 6. 


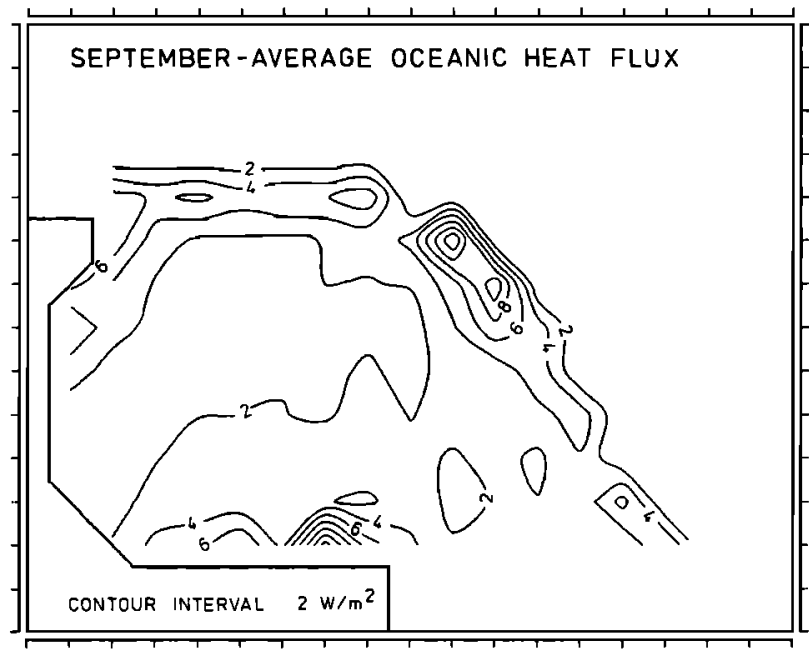

Fig. 8. Simulated mean September oceanic heat flux in the Weddell Sea for the standard experiment.

but the winter extent is larger in the fixed mixed layer case and the winter maximum occurs about 30 days earlier. This phase delay is typical for the prognostic mixed layer model with an exponential pycnocline. An explanation is given in section 3.4 , where the standard model is compared to the Kraus-Turner model.

Comparing the performance of the standard model and the fixed mixed layer case one should keep in mind, however, that the parameters of the sea ice model were tuned to fit the model results to observations using a fixed mixed layer depth [Hibler and Ackley, 1983]. These parameter values (also used in this study) are not necessarily the optimal ones for the extended sea ice-mixed layer-pycnocline model. Although it seems expedient to retune the parameters, we think this is only meaningful when the complete ocean circulation is included. This will be the topic of a subsequent paper.

\subsection{No Sea Ice Advection (Thermodynamics Only)}

In the next experiment the ice velocity was set to zero, i.e., only thermodynamic ice growth or melt was included.

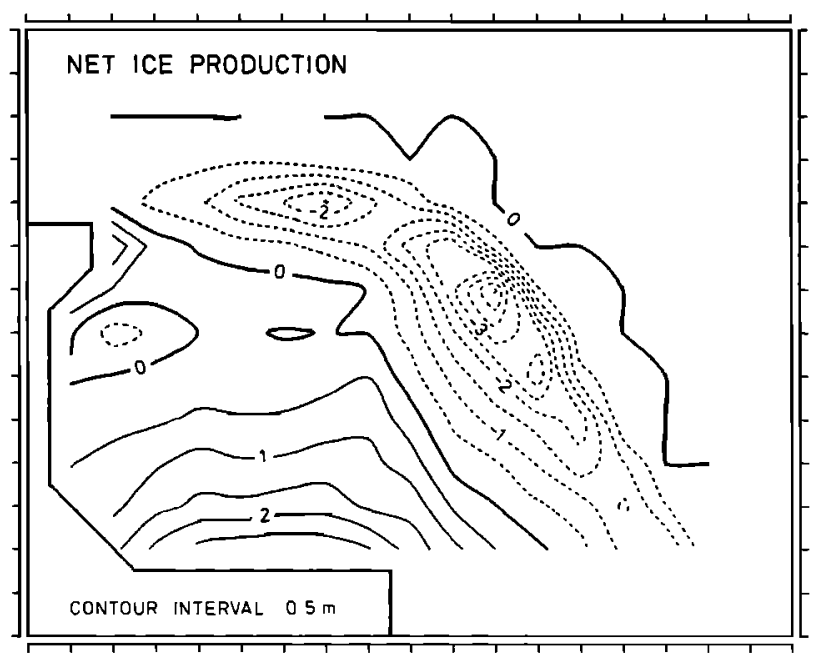

Fig. 9. Simulated net ice production in the Weddell Sea for the standard experiment.

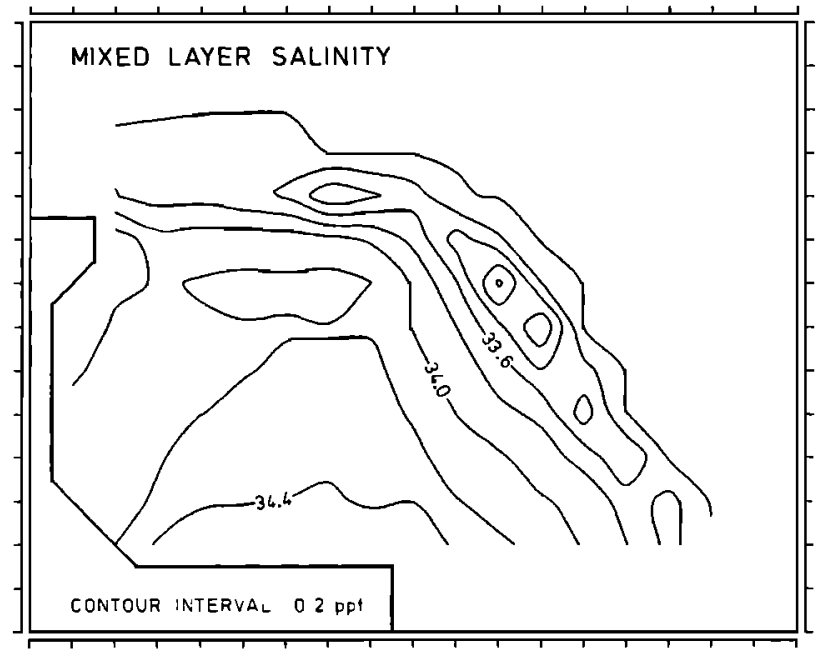

Fig. 10. Simulated standard mixed layer salinity in the Weddell Sea on October 6.

In the mixed layer model a constant turbulent kinetic energy input corresponding to an ice velocity of $0.1 \mathrm{~m} / \mathrm{s}$ was used.

The resulting seasonal amplitudes for volume and extent were reduced by $50 \%$, while the phases remained unchanged (dashed lines, Figure 11). The thermodynamics-only model exhibits a much larger summer ice extent and a substantial increase in ice volume throughout the whole year. These results are similar to those of Hibler and Ackley [1983].

The sea ice thickness pattern follows the thermodynamic forcing and accordingly has its highest values in the southern part of the grid. Generally the thickness is increased by $1 \mathrm{~m}$ compared to the standard experiment. The mixed layer depth is substantially reduced and reaches a maximum of only $80 \mathrm{~m}$ in the southern Weddell Sea. Due to smaller entrainment rates the average oceanic heat flux is only one third of the standard value. The net freezing rate is negligible (as it should be for a thermodynamic model that has reached a cyclostationary state). The salinity has accordingly no pronounced minimum at the ice edge.

Also shown in Figure 11 are the seasonal cycles of extent and volume for the thermodynamic model with the fixed mixed layer model (dotted lines). Comparing these results to Figure 3 it is apparent that the inclusion of a prognostic mixed layer model has a larger effect on the thermodynamics-only model than on the full model. This means that a model that includes sea ice dynamics is less sensitive to different ocean models than a purely thermodynamic sea ice model. This reduced sensitivity is a typical feature of a dynamic sea ice model, which we will also encounter in the polynya and paleoclimate experiments (sections 3.5 and 3.6).

The reduced sensitivity of the full model can be explained by the interaction between the dynamics and the thermodynamics of the sea ice model. In regions where the thermodynamics reduces the ice thickness, the ice gets weaker and the dynamics, under favorable conditions, i.e., convergence, can readily increase the ice thickness (by importing ice into the region). In regions where the dynamics reduces the ice thickness (divergence), the thermodynamics, under favorable conditions, i.e., cooling, can easily increase the sea ice thickness. These interactions produce a negative feedback, which tends to stabilize the solution. 


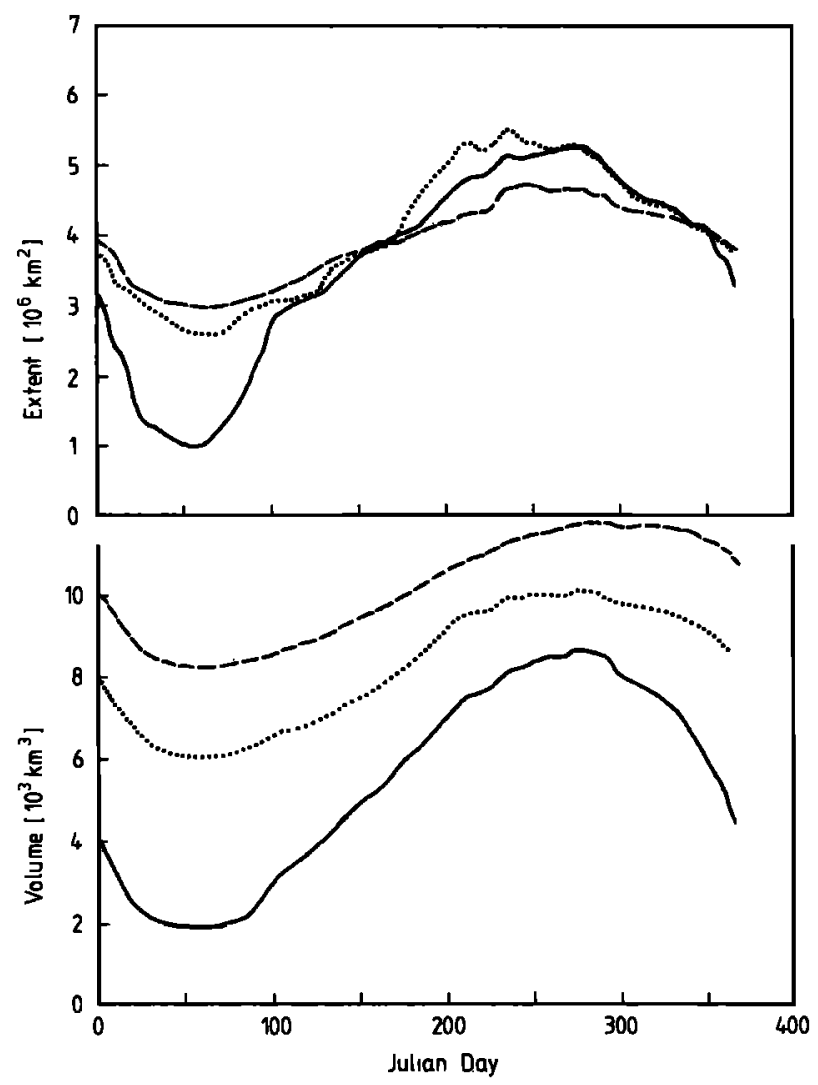

Fig. 11. Seasonal cycle of the integrated ice covered area (upper panel) and ice volume (lower panel) for the standard experiment (solid lines) and the thermodynamics-only run using the prognostic (dashed lines) and fixed mixed layer model (dotted lines).

\subsection{Kraus-Turner Models}

3.4.1. Case where $a_{S, T}=1.0$. The results of coupling the original Kraus-Turner (KT) model $\left(a_{S, T}=1.0\right)$ to the full sea ice model (dotted lines) are compared in Figure 12 to the standard experiment (solid lines). The KT model gives a more pronounced seasonal cycle (smaller minimum, larger maximum) for the sea ice extent, and the winter maximum extent occurs 50 days earlier than in the standard run. Furthermore the KT model produces only one half of the standard sea ice volume. The seasonal phases of the ice volume are similar for both mixed layer models.

The sea ice velocities do not differ substantially between the KT and standard models. The mixed layer depth in the open ocean is larger in the standard experiment, but under the ice the mixed layer is deeper for the KT model. The KT oceanic heat flux under the ice is larger (by a factor of 4) than the standard one. The net freezing rate of the KT model is accordingly smaller than in the standard experiment and the salinity minimum at the ice edge is less pronounced.

The basic difference of the KT experiment is the substantially larger oceanic heat flux, which explains all other differences described above. This large entrainment heat flux is due to the generally larger temperature discontinuity at the base of the mixed layer in the KT model $\left(a_{S, T}=1\right)$ than in the standard model (typically $a_{S, T} \approx 0.3$ ). The temperature increase with depth destabilizes the density stratification

$$
\Delta \rho=\beta \Delta S-\alpha \Delta T
$$

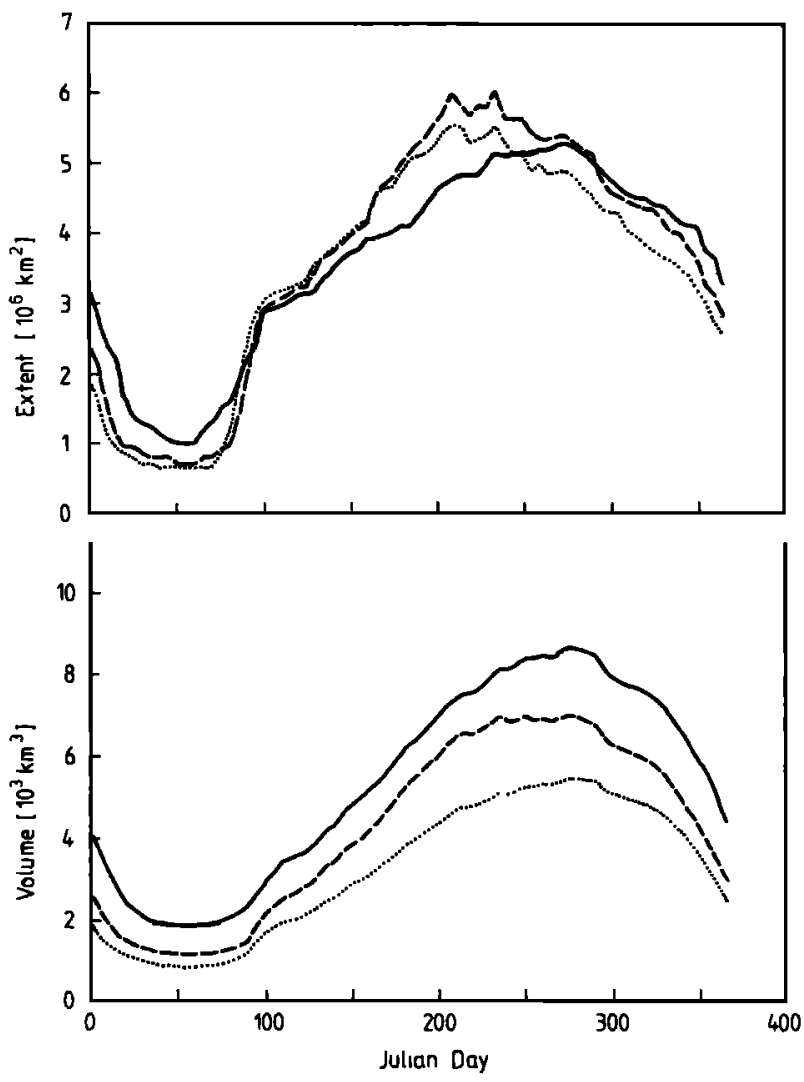

Fig. 12. Seasonal cycle of the integrated ice-covered area (upper panel) and ice volume (lower panel) for the standard experiment (solid lines) and the Kraus-Turner experiments with $a_{S, T}=1.0$ (dotted lines) and $a_{S, T}=0.3$ (dashed lines).

where both $\Delta S$ and $\Delta T$ are positive under the ice. Thus, for similar kinetic energy inputs or freezing rates, the KT model will have deeper entrainment and a larger heat flux.

In the open ocean, where $\Delta T$ is negative, the stability of the KT model is generally larger than the standard case. As a result the mixed layer is shallower and, for the same cooling rates, the mixed layer temperature reaches the freezing point sooner, allowing ice to form earlier. This explains the phase shift of the ice extent observed in Figure 12.

To investigate the phase difference of the annual cycle in more detail two experiments were performed with a constant kinetic energy input for the KT and standard mixed layer models. Figure 13 presents the seasonal cycle of the average atmospheric freezing rate (upper panel) and the oceanic heat flux under the ice (lower panel). Although the atmospheric freezing rate is quite similar for both mixed layer models, there is an apparent magnitude and phase difference of the oceanic heat flux. The increased entrainment heat flux of the KT model is a result of the larger temperature jump and the stronger entrainment rates, due to the reduced stability.

The oceanic heat flux into the mixed layer, $Q_{o}$, is proportional to the entrainment rate multiplied by the temperature difference in the entrainment zone. Under the ice we find

$$
Q_{o}=\left(T^{*}-T\right) W_{e} \equiv a_{T}\left(T_{b}-T_{j}\right) W_{e}
$$

In the $\mathrm{KT}$ model $a_{T}=1$, and therefore the temperature difference is constant. In the standard model, on the other 

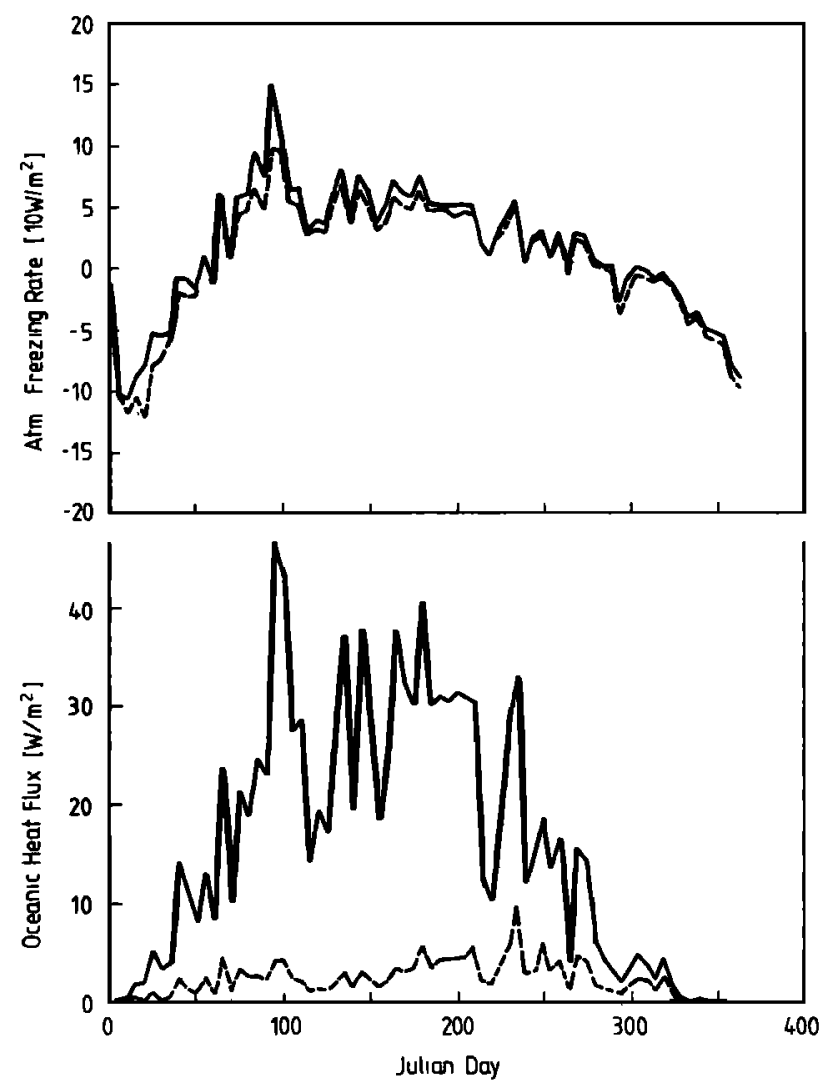

Fig. 13. Seasonal cycle of the atmospheric freezing rate (upper panel) and the entrainment heat flux into the mixed layer (lower panel) for the standard mixed layer model (dashed lines) and the Kraus-Turner model with $a_{S, T}=1.0$ (solid lines) using a constant kinetic energy input.

hand, the temperature difference increases due to the evolution of the thermocline scale $d_{T}$, which determines $a_{T}$ in (20). For $\delta \ll d_{T}$, (20 turns into

$$
a_{T}=\delta /\left(2 d_{T}\right)
$$

Since $d_{T}$ decreases during the course of winter, $a_{T}$ and therefore the temperature gradient within the entrainment zone increase for the standard model. This results in the delay of the winter maximum entrainment heat flux for the standard experiment.

In addition to the large entrainment heat flux the entrained salt flux is also large, so that the surface salinity of the KT experiment is substantially higher than the surface salinity of the standard model.

3.4.2. Case where $a_{S, T}=0.3$. In the original two-layer Kraus-Turner model the vertical resolution below the mixed layer is rather poor and the entrainment heat flux is described by a temperature discontinuity which is given as the difference between the surface temperature and the mean temperature of the second layer, i.e., the entrainment zone extends throughout the entire second layer of the model. In reality, the entrainment zone and therefore the corresponding temperature and salt differences in the entrainment parameterization are considerably smaller. In order to account for this fact the KT model was applied with $a_{S, T}=0.3$, thereby reducing the entrainment fluxes of heat and salt. This parameterization improves the ice thickness (volume) drastically throughout the year and yields a better ice extent in summer, but the winter ice extent is slightly too large (Figure 12, dashed lines). Experiments with different (constant) values for $a_{S, T}$ did not improve the results. In these experiments the phase difference of the seasonal cycle of the extent compared to the standard run did not change either. The phase seems to be a result of the seasonal evolution of the temperature and salinity gradients at the base of the mixed layer which in the KT model is constant for temperature and a linear function of $S_{b}-S$. In the standard mixed layer model the gradients are in addition exponentially dependent on the halocline and thermocline scales $d_{S}$ and $d_{T}$, which evolve in time.

Since the incorporation of an advective scheme is far simpler in the KT model, it seems appropriate to develop a KT model with a time-dependent expression for $a_{S, T}$, which has similar characteristics as in (20).

\subsection{Polynya Experiments}

Two mechanisms that destabilize the oceanic stratification, allowing stronger entrainment of warm water and a subsequent reduction of the sea ice thickness, were dis-
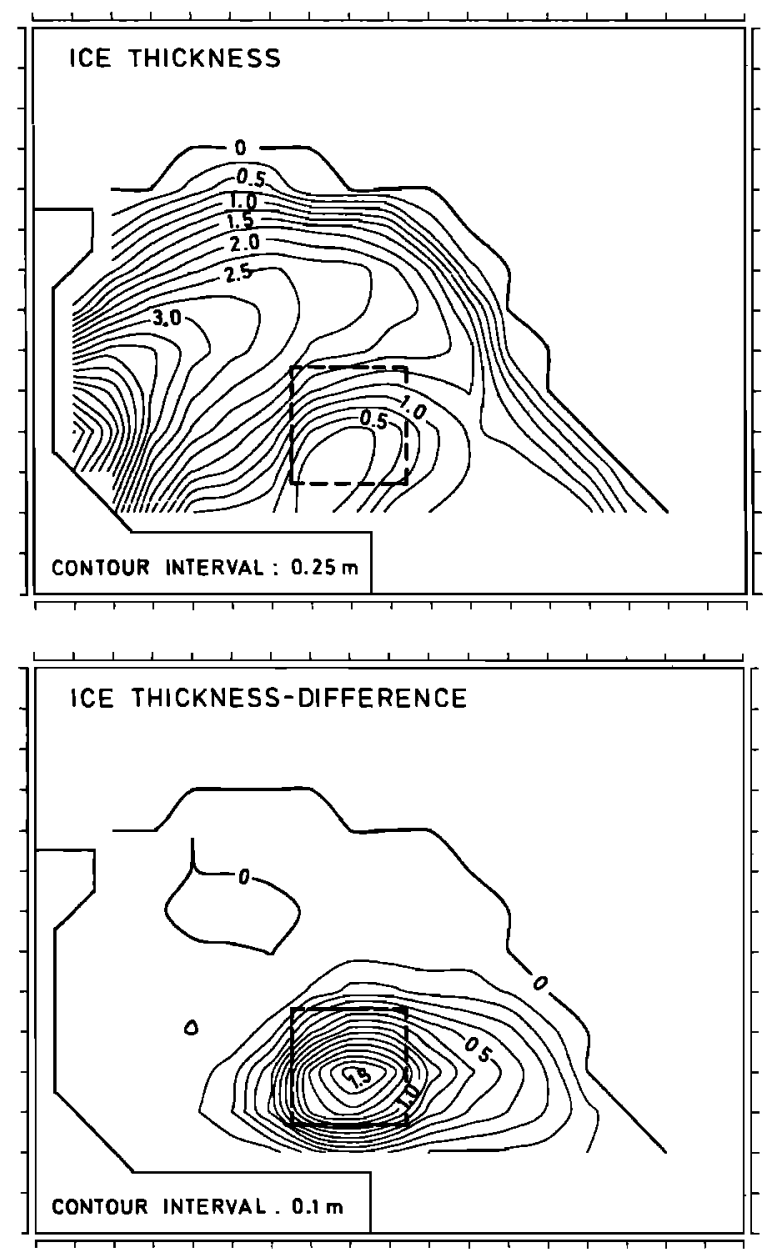

Fig. 14. Sea ice thickness (upper panel) of the polynya experiment using the standard dynamic model on day 280 (October 6), 75 days after the end of the "warm cell perturbation." The dashed line indicates the region where the perturbation was applied. The lower panel shows the corresponding ice thickness difference between the polynya experiment and a simulation without perturbation. 

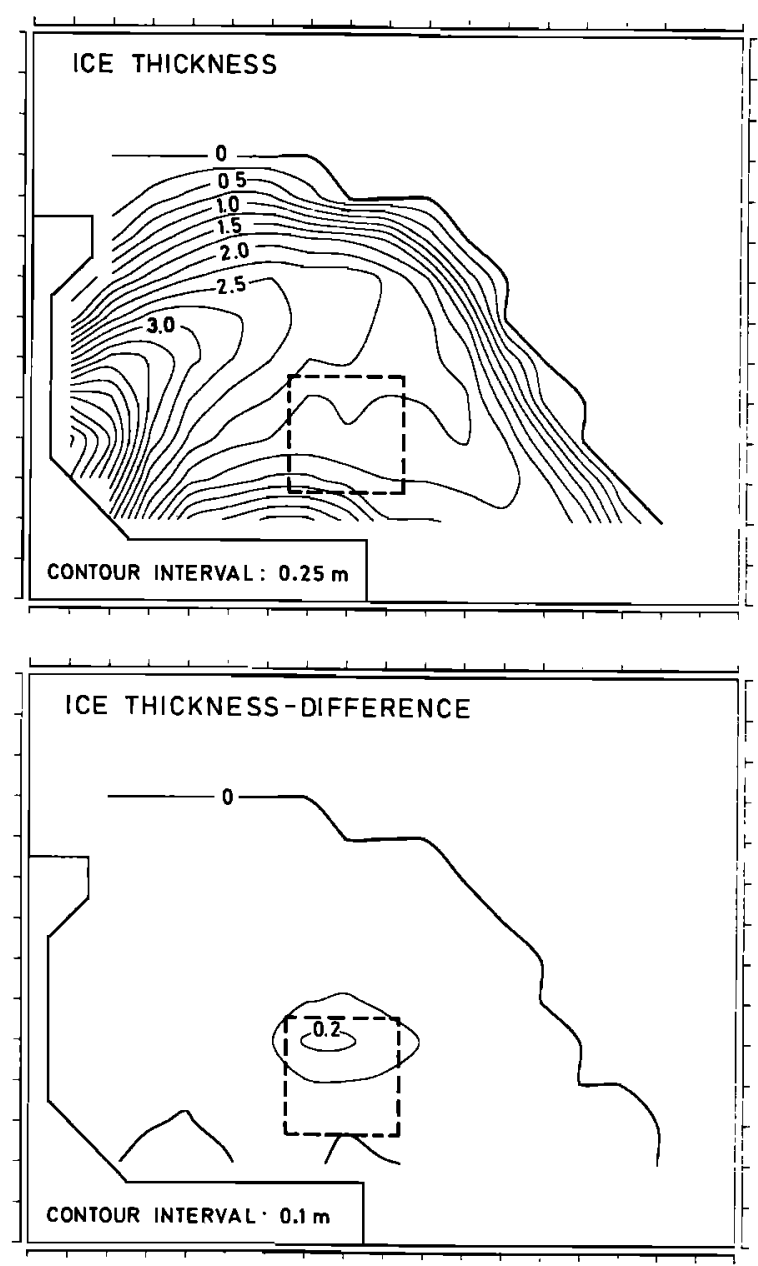

Fig. 15. Same as Figure 14 for day 640 (October 1), 435 days after the end of the "warm cell perturbation."

cussed in Lemke [1987]. In order to investigate the effect of the sea ice dynamics on the formation and termination of a polynya, one of these mechanisms will also be tested here.

During a cruise in the Weddell Sea, Gordon and Huber [1984] observed large warm subsurface eddies which traveled from the east into the Weddell Sea. These warm cells lifted the mixed layer base significantly and increased the pycnocline temperature, leading to more intense entrainment of warm and salty water.

In our polynya experiment we modeled the warm cells by resetting the mixed layer depth to $40 \mathrm{~m}$ for 50 days beginning with June 3 , at a time when the mixed layer is normally deepening, and by increasing $T_{b}$ by $1^{\circ} \mathrm{C}$. After 50 days, $T_{b}$ is again relaxed to the standard value of $0.6^{\circ} \mathrm{C}$. This perturbation was applied to nine grid points in the southern Weddell Sea. The initial conditions for this experiment were taken from December 31 of the fifth year of the standard run.

The response of the sea ice thickness on October $6(75$ days after the end of the perturbation) is shown in Figure 14 (upper panel). The lower panel of Figure 14 displays the sea ice thickness difference between the polynya experiment and a simulation without the perturbation. It is clear that the "warm cell" perturbation leads to a strong reduction of the sea ice thickness of up to $1.5 \mathrm{~m}$. Due to the ice advection the extent of the response pattern is larger than the actual perturbation area (dashed line). The zonal scale of the response is more pronounced than the meridional one since this area is in the southern portion of the Weddell gyre.

One year later (October 1) the sea ice thickness has nearly returned to normal conditions (Figure 15). This is in contrast to the work by Lemke [1987] where a thermodynamic sea ice model was used. In order to investigate whether the sea ice dynamics reduces the lifetime of a polynya, a similar experiment was performed with the thermodynamics-only version of the Weddell sea ice model. Figure 16 indicates that the magnitude of the response of the thermodynamics-only model in the winter following the perturbation is similar to that of the dynamic model, but the response is limited to the warm cell area, where the perturbation was applied. From Figure 17 it is evident that one year later the thermodynamics-only model still shows a pronounced reduction of the ice thickness.

These experiments show that the sea ice dynamics increases the spatial scale of the response, and it reduces the lifetime of the polynya response by importing ice into the thin ice and low compactness region, where there is less resistance to convergence. In other words, the dynamic sea ice model is less sensitive to short-time perturbations than the purely thermodynamic model. Experiments with a larger warm cell perturbation area ( 24 grid points) showed a larger spatial scale and a slightly increased lifetime of the response.
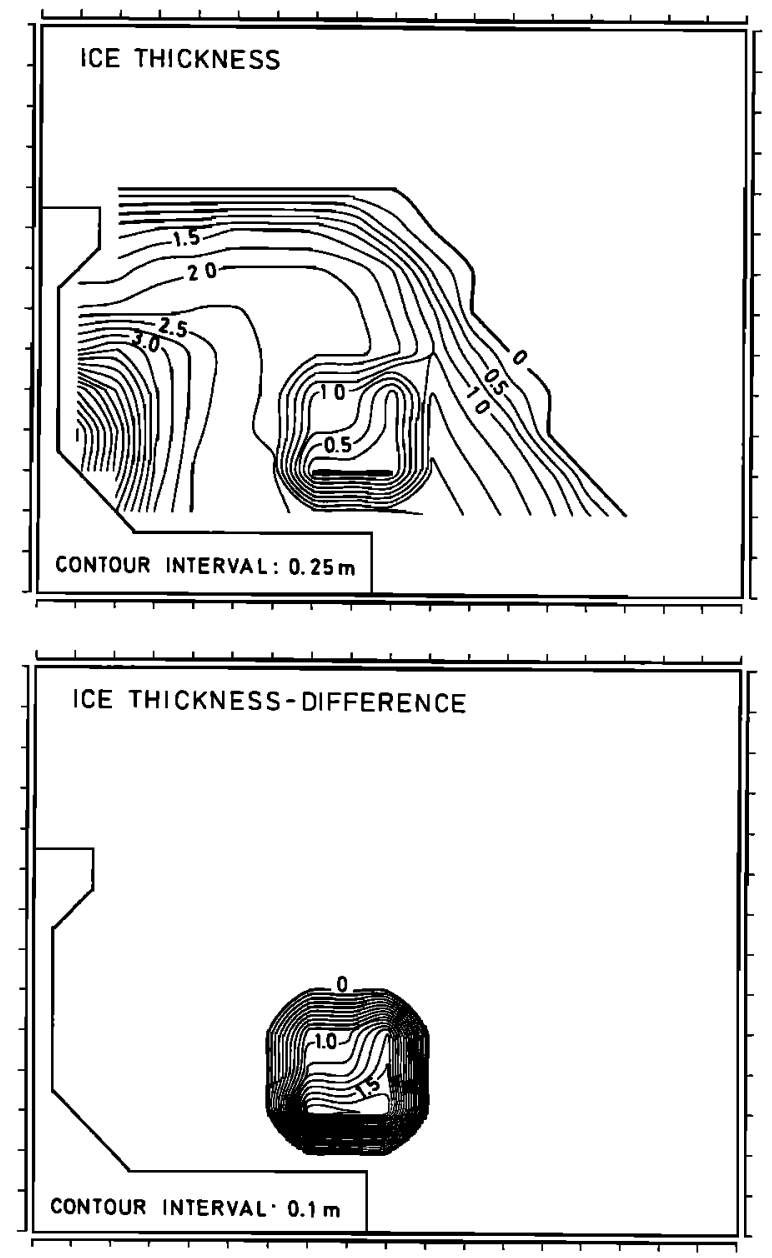

Fig. 16. Same as Figure 14 using a thermodynamics-only model. 

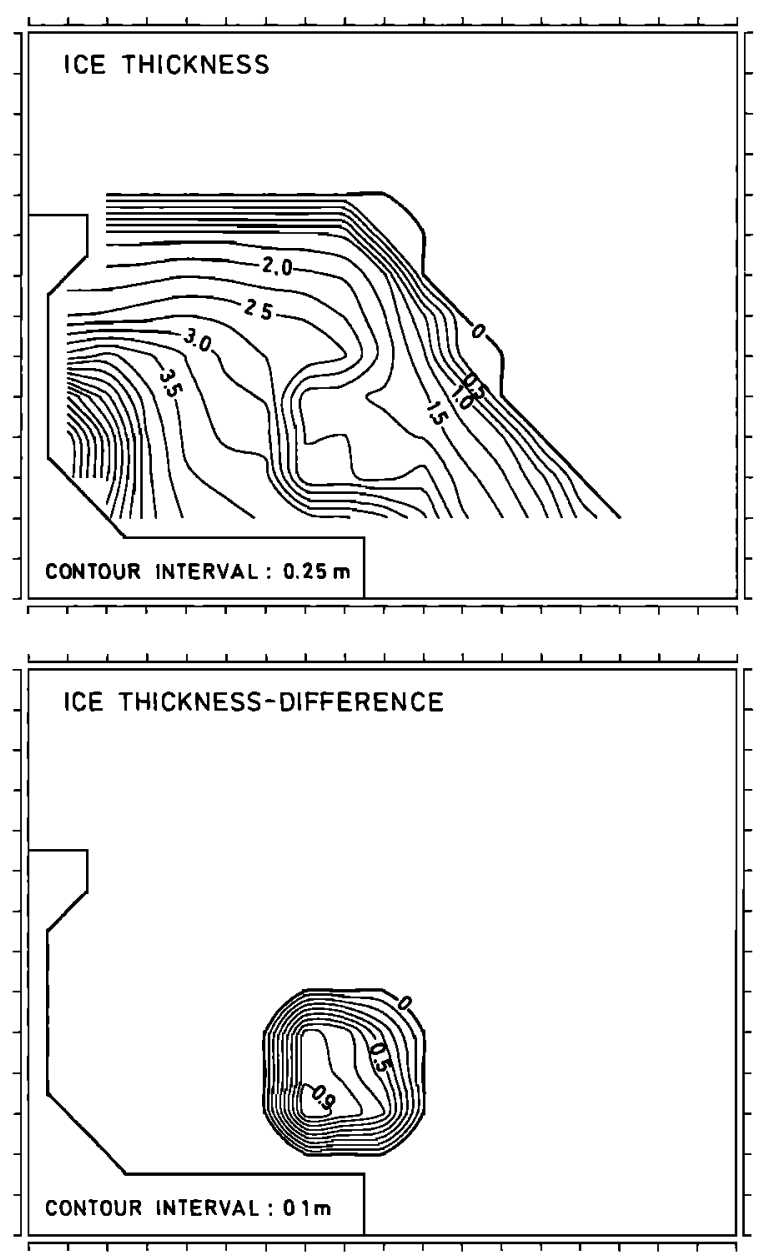

Fig. 17. Same as Figure 15 using a thermodynamics-only model.

\subsection{Paleoclimate Experiments}

The deep ocean boundary conditions and the atmospheric forcing during earlier paleoclimatic periods are believed to have been quite different from today's values. In this section the response of the standard model to boundary conditions corresponding to different possible paleoclimatic epochs is presented. The results are compared with the standard experiment discussed in section 3.1. The different experiments are similar to those of Lemke [1987] who used the same mixed layer model coupled to a simple thermodynamic sea ice model.

Figure 18 presents the results of four response experiments: (1) The deep ocean temperature was reduced to $0^{\circ} \mathrm{C}$ everywhere. (2) The incoming solar radiation was reduced by $10 \%$. (3) The air temperature was reduced by $2^{\circ} \mathrm{C}$ everywhere. (4) All three boundary modifications were applied simultaneously. It is obvious that the seasonal response increases from experiment (1) to (4). A $10 \%$ reduction of the solar radiation leads to more ice than the cooling of the deep ocean. And the reduction of the atmospheric temperatures by $2^{\circ} \mathrm{C}$ yields even more sea ice.

The application of all three modifications of the boundary conditions resulted in an expansion of the ice-covered area of $0.7 \times 10^{6} \mathrm{~km}^{2}$, and the volume increased by $2 \times 10^{3} \mathrm{~km}^{3}$. The velocity pattern for this experiment was similar to the standard one. The winter ice thickness increased by about
$0.3 \mathrm{~m}$, and the mixed layer depth was larger by about $20 \mathrm{~m}$. The magnitude of the oceanic heat flux also increased, whereas the pattern remained similar. Due to the larger atmospheric cooling the net freezing rate was enhanced by $0.5 \mathrm{~m} / \mathrm{yr}$, and the salinity gradients increased accordingly.

Another experiment with a larger surface freshwater flux (melting ice sheets) resulted in a similar seasonal response of ice thickness and extent as for the cold deep ocean experiment. The velocity and thickness patterns differed only slightly from the standard run, but due to the enhanced stability the mixed layer depth was reduced significantly by about $50 \mathrm{~m}$. Accordingly the oceanic heat flux and the net freezing rate decreased. Due to the larger freshwater flux the surface salinity was reduced by $0.2-0.4 \%$.

In general the response of the dynamic-thermodynamic sea ice model to paleoclimatic boundary conditions is less pronounced than in the experiments of Lemke [1987] who used a simple thermodynamic sea ice model. To show this also for our Weddell Sea region we compared the results of the thermodynamics-only model (section 3.3 ) with the response of this model to a reduction of the deep ocean temperatures (Figure 19). Comparing the results of Figure 18 for $T_{b}=0^{\circ} \mathrm{C}$ with Figure 19 we see that the full model is less sensitive to modifications of the deep ocean boundary conditions than the thermodynamics-only model. This holds true also for modifications of the atmospheric boundary conditions.
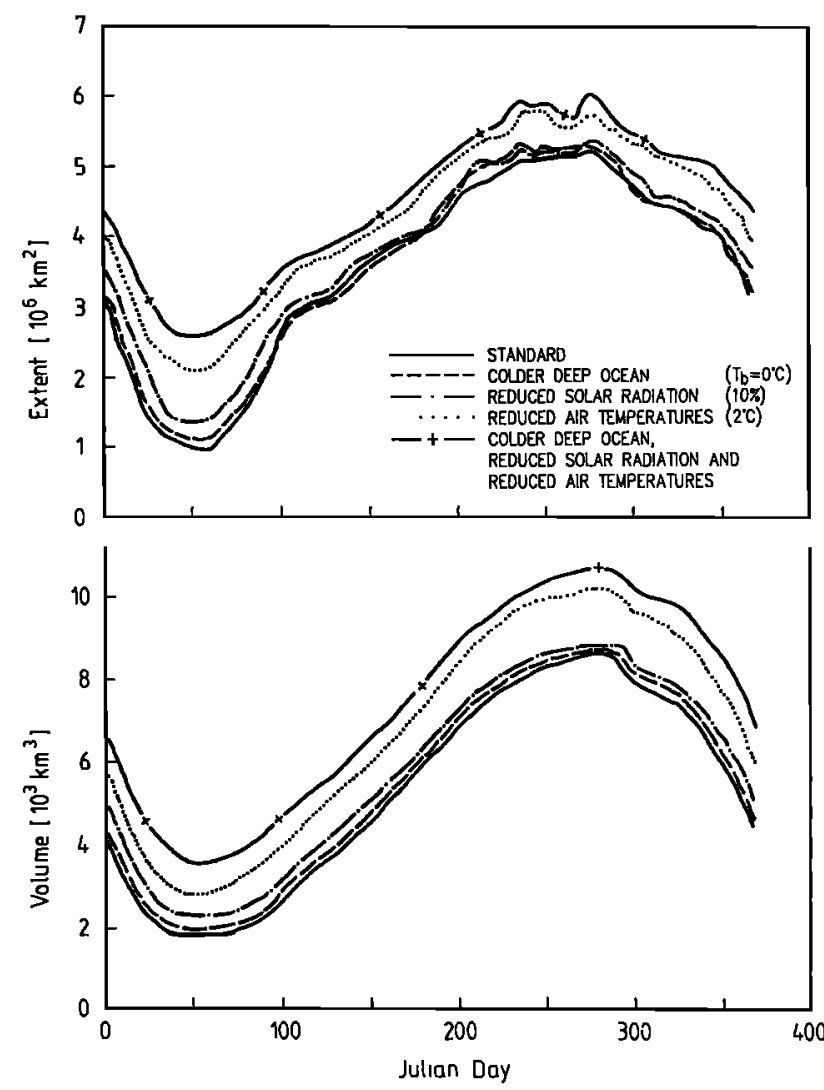

Fig. 18. Seasonal cycle of the integrated ice-covered area (upper panel) and ice volume (lower panel) for different paleoclimate experiments. 

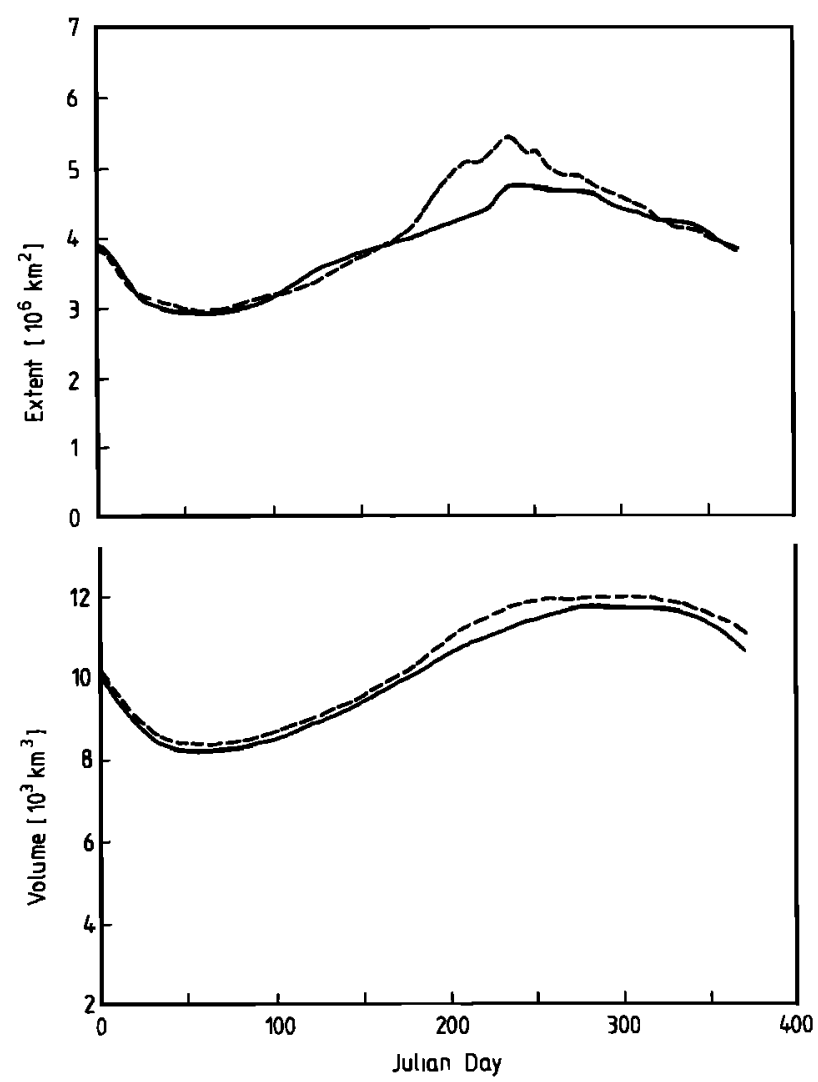

Fig. 19. Seasonal cycle of the integrated ice-covered area (upper panel) and ice volume (lower panel) for the thermodynamicsonly model with (dashed lines) and without (solid lines) colder deep ocean temperatures.

\section{Conclusions}

Experiments with a coupled sea ice-mixed layer model in the Weddell Sea show the well known gyre circulation with a divergent sea ice drift, and accordingly thinner ice, larger freezing rates, higher salinities, and deeper mixed layers in the south off the Antarctic continent.

The results indicate that the vertical oceanic heat flux is not constant as previously assumed in sea ice modeling, but shows a pronounced time and spatial dependence. The largest values are generally found at the ice edge and in the divergent drift region in the southern Weddell Sea, where large entrainment rates occur. In summertime relatively large entrainment heat fluxes are produced by the surface stress induced by wind and sea ice drift, which is generally higher in this season. Because of the rather poor vertical resolution below the mixed layer, the original two-layer Kraus-Turner model generated a considerably higher oceanic heat flux as compared to the standard mixed layerpycnocline model, which includes a more sophisticated pycnocline representation.

Experiments with short-time disturbances, such as a warm eddy, which destabilize the oceanic stratification compared with the normal seasonal conditions, show that such shortlived perturbations are capable of producing an anomalous reduction of the sea ice thickness, but the sea ice dynamics reduces the lifetime of such a polynya response considerably compared to a thermodynamics-only model. This is due to the fact that under convergent winds sea ice is imported into the thin ice-low compactness region, which has only a small ice strength, and is melted, thereby increasing the oceanic stratification and reducing the entrainment. This suggests that the observed long life of the polynya in 1974/1975 [Carsey, 1980] must have been sustained by anomalous meteorologic or oceanic conditions.

This means that the dynamic-thermodynamic sea ice model is less sensitive to short-time perturbations than the thermodynamics-only model, and from paleoclimate experiments it is evident that this is also true for modifications of the atmospheric and deep ocean boundary conditions.

Acknowledgments. The authors would like to thank K. Hasselmann for comments on an earlier version of the paper, and $M$. Grunert for drafting the figures. This work was partly supported by the Max-Planck-Institute für Meteorologie. Additional funding was received from the Office of Naval Research under contract N0001486-K-0751 (W.B.O.) and N00014-86-K-0695 (W.D.H.), and from the National Science Foundation under grant DPP-8518747 (W.B.O.). This is contribution $\mathbf{7 0 7 3}$ from Woods Hole Oceanographic Institution.

\section{REFERENCES}

Ackley, S. F., Mass balance aspects of Weddell Sea pack ice, $J$. Glaciol., 24, 391-406, 1979.

Ackley, S. F., Sea ice-atmosphere interactions in the Weddell Sea using drifting buoys, Sea Level, Ice, and Climatic Change, IAHS Publ., 131, 177-191, 1981.

Ackley, S. F., A. J. Gow, K. R. Buck, and K. M. Golden, Sea ice studies in the Weddell Sea aboard USCGS Polar Sea, Antarct. J. U. S., 15(5), 84-86, 1980.

Carsey, F. D., Microwave observation of the Weddell polynya, Mon. Weather Rev., 108, 2032-2044, 1980.

Deacon, G. E. R., The Weddell gyre, Deep Sea Res., 26A, 981-995, 1979.

Foster, T. D., and E. C. Carmack, Temperature and salinity structure in the Weddell Sea, J. Phys. Oceanogr., 6, 36-44, 1976.

Gordon, A. L., Seasonality of Southern Ocean sea ice, J. Geophys. Res., 86, 4193-4197, 1981.

Gordon, A. L., and B. A. Huber, Thermohaline stratification below the Southern Ocean sea ice, J. Geophys. Res., 89, 641-648, 1984.

Gordon, A. L., E. Molinelli, and T. Baker, Large-scale relative dynamic topography of the Southern Ocean, J. Geophys. Res., 83, 3023-3032, 1978.

Gordon, A. L., D. G. Martinson, and H. W. Taylor, The winddriven circulation in the Weddell-Enderby Basin, Deep Sea Res., 28A, 151-163, 1981.

Gordon, A. L., C. T. A. Chen, and W. G. Metcalf, Winter mixed layer entrainment of Weddell deep water, J. Geophys. Res., 89, 637-640, 1984.

Hibler, W. D., III, A dynamic thermodynamic sea ice model, $J$. Phys. Oceanogr., 9, 815-846, 1979.

Hibler, W. D., III, The role of sea ice dynamics in modeling $\mathrm{CO}_{2}$ increases, in Climate Processes and Climate Sensitivity, Geophys. Monogr. Ser., vol. 29, edited by J. E. Hansen and T. Takahashi, pp. 238-253, AGU, Washington, D. C., 1984.

Hibler, W. D., III, and S. F. Ackley, Numerical simulation of the Weddell Sea pack ice, J. Geophys. Res., 88, 2873-2887, 1983.

Lemke, P., A coupled one-dimensional sea ice-ocean model, $J$. Geophys. Res., 92, 13,164-13,172, 1987.

McPhee, M. G., The effect of the oceanic boundary layer on the mean drift of pack ice: Application of a simple model, J. Phys. Oceanogr., 9, 388-400, 1979.

McPhee, M. G., and J. D. Smith, Measurement of the turbulent boundary layer under pack ice, J. Phys. Oceanogr., 6, 696-711, 1976.

Niiler, P. P., and E. B. Kraus, One-dimensional models of the upper ocean, in Modelling and Prediction of the Upper Layers of the Ocean, edited by E. B. Kraus, pp. 143-172, Pergamon, New York, 1977.

Owens, W. B., and P. Lemke, Sensitivity studies with a sea 
ice-mixed layer-pycnocline model in the Weddell Sea, J. Geophys. Res., this issue.

Parkinson, C. L., and W. M. Washington, A large-scale numerical model of sea ice, J. Geophys. Res., 84, 311-337, 1979.

Semtner, A. J., A model of the thermodynamic growth of sea ice in numerical investigations of climate, J. Phys. Oceanogr., 6, 379 $389,1976$.

Stössel, A., P. Lemke, and W. B. Owens, Coupled sea ice-mixed layer simulations for the Southern Ocean, J. Geophys. Res., this issue.

Toole, J. M., Sea ice, winter convection, and the temperature minimum layer in the Southern Ocean, J. Geophys. Res., 86, 8037-8047, 1981.

Wadhams, P., M. A. Lange, and S. F. Ackley, The ice thickness distribution across the Atlantic sector of the Antarctic Ocean in midwinter, J. Geophys. Res., 92, 14,535-14,552, 1987.

Washington, W. M., A. J. Semtner, C. Parkinson, and L. Morrison,
On the development of a seasonal change sea ice model, J. Phys. Oceanogr., 6, 679-685, 1976.

Zwally, H. J., J. C. Comiso, C. L. Parkinson, W. J. Campbell, F. D. Carsey, and P. Gloersen, Antarctic sea ice, 1973-1976: Satellite passive-microwave observations, NASA Spec. Publ., SP-459, $1-206,1983$.

W. D. Hibler III, Dartmouth College, Hanover, NH 03755.

P. Lemke, Alfred Wegener Institute for Polar and Marine Research, Am Handelshafen 12, D-2850 Bremerhaven, Federal Republic of Germany.

W. B. Owens, Woods Hole Oceanographic Institution, Woods Hole, MA 02543.

(Received June 7, 1989;

accepted July 25, 1989.) 